\title{
Analysis of the relationship between the length of eye fixation and the parameters of advertisements visible from the road
}

\author{
Tomasz Mackun ${ }^{1, *}$, and Joanna Żukowska ${ }^{1}$ \\ ${ }^{1}$ Gdansk University of Technology, Faculty of Civil Engineering, 11/12 Narutowicza Str., Gdansk, \\ Poland
}

\begin{abstract}
In Poland, many advertising signs addressed to motorists are located along the roadside. Advertisements do not serve any traffic related purpose and can distract drivers making them less reliable and as a consequence, reduce road safety. The existing regulations only apply to the carriageway. The research is conducted as part of the RID project. The objective of the RID project is to create a "Manual for positioning roadside advertising signs". The research aims to establish whether drivers look at roadside advertising and for how long. An additional goal is to investigate the correlation between the number and duration of the driver's eye fixation and the parameters of advertising media. In their work the authors use a mobile eye tracker. The study included a group of 60 drivers who drove on a section of about $110 \mathrm{~km}$ which included roads of various technical classes, different cross-sections and featured a varied roadside development pattern. 2,900 advertising carriers were inventoried on the route. Almost $30 \%$ of all advertising media drew the gaze. The billboards on which fixations were registered in the studied group were inventoried in detail for their geometrical, location or content parameters. The authors of the article present the relations between the parameters and their ability to attract the attention of drivers depending on the number of fixations and their duration.
\end{abstract}

\section{Introduction}

The roads in Poland are lined up with advertising targeting motorists. Advertising is not designed to guide traffic and may be a source of driver distraction. This may affect driving performance and adversely impact road safety [1-3]. Existing regulations [4] are limited and ineffective. While advertising is not allowed within the roadside zone outside built-up areas, built-up area billboards can be put up under road authority rules for a fee. Roadside adverts are allowed or disallowed by the road's authority. The act also bans advertising visible from the road if located within the distances listed in Table 1 in built-up and non-built-up areas respectively. Existing advertising was analysed for its location. Advertisers were found to locate their billboards where doing this is prohibited and where it is not. If located past the statutory boundary, advertising is also clearly visible from the road. In addition, as we know

\footnotetext{
* Corresponding author: tomasz.mackun@pg.edu.pl
} 
from practice, none of the public services are willing to manage this, i.e. to allow, monitor or remove billboards. Advertising which the Building Law [5] considers a structure are the responsibility of the building supervision inspector. When interviewed, road authorities suggested that building supervision inspectors do not see advertising as a distraction to drivers and are not happy to intervene. No services are responsible for advertising which is not defined as a structure and no effective actions are possible.

Table 1. Distance from the road boundaries where advertising cannot be located.

\begin{tabular}{|c|c|c|c|}
\hline No. & Type of road & $\begin{array}{c}\text { In built-up } \\
\text { area }\end{array}$ & $\begin{array}{c}\text { Outside built- } \\
\text { up area }\end{array}$ \\
\hline 1 & Motorway & $30 \mathrm{~m}$ & $50 \mathrm{~m}$ \\
\hline 2 & Express Road & $20 \mathrm{~m}$ & $40 \mathrm{~m}$ \\
\hline 3 & General Access Road: national & $10 \mathrm{~m}$ & $25 \mathrm{~m}$ \\
\hline 4 & General Access Road: voivodeship & $8 \mathrm{~m}$ & $20 \mathrm{~m}$ \\
\hline 5 & General Access Road: municipality & $6 \mathrm{~m}$ & $15 \mathrm{~m}$ \\
\hline
\end{tabular}

Adopted in 2015, the "Act revising certain acts to reinforce landscape protection measures" [6], allows municipalities, under local law, to adopt resolutions which govern the conditions of advert placement and the collection of appropriate fees. Yet the Act fails to mention the negative impact advertising visible from the road may have on road safety. Road authorities have no say over the document. It is very likely that the effect of advertising on safety will not be considered. What may also happen is the presence of a different standard within the roadside which goes against the move towards standardisation of road parameters, signs and measures. It is important to have standard solutions, if we do not want motorists to be astonished to see different solutions as they cross municipality boundaries.

To achieve Vision Zero and deliver on the targets set out in the National Safety Programme 2013 - 2020 [7], i.e. to at least reduce annual fatalities by $50 \%$ and seriously injured by at least $40 \%$ by 2020 , all possible road hazards should be eliminated. It is important to create clear and enforceable rules nationwide as regards the location and form of advertising visible from the road. This article describes research conducted on Poland's roads in real conditions using a wearable eye tracker.

\section{Objectives}

The study is part of the RID project. The objective of RID is to develop a "Manual for positioning roadside advertising signs". It will give clear guidance for locating advertising and the relevant rules. The objective of the work is to check whether drivers look at advertising visible from the road. This will be measured with the number of glances at advertising and the time spent looking. There is an additional goal which is to establish a correlation between the number and duration of glances and the parameters of advertising media.

\section{Method}

The study was conducted in the following steps: a) Select study sections, b) Make an inventory and analysis of advertising media on the study section, c) Select study subjects, d) Conduct eye tracker tests, e) Results and data analysis. 


\subsection{Selecting study sections}

A total of $96 \mathrm{~km}$ of different road classes and cross-sections running across different functional areas were selected. The study ran in a loop starting and ending in GdańskWrzeszcz. The advertising included adverts visible for motorists moving in one direction of traffic (clockwise). The section includes a motorway, express road and lower class roads. The section runs across non-built-up and built-up areas. The following is the share of the sections:

- non-built-up area $-10.8 \mathrm{~km}(11.25 \%$ of the entire route),

- built-up area $-85.2 \mathrm{~km}(88.75 \%$ of the entire route).

The route was divided into sections of specific road categories and roadside development:

- motorway $-15.7 \mathrm{~km}(16.4 \%$ of the entire route),

- $\quad$ express road $-25.4 \mathrm{~km}(26.5 \%$ of the entire route),

- county capital (Gdańsk) - $24.3 \mathrm{~km}(25.3 \%$ of the entire route),

- $\quad$ small towns - Pruszcz Gdański, Tczew $-8.3 \mathrm{~km}$ (8.6 \% of the entire route),

- transit roads through small towns - Łęgowo, Różyny, Skowarcz, Pszczółki, Miłobądz, Szpęgawa, Stanisławie $-11.5 \mathrm{~km}(12.0 \%$ of the entire route),

- $\quad$ outside built-up areas $-10.8 \mathrm{~km}(11.3 \%$ of the entire route).

\subsection{Making an inventory and analysing advertising media on the study section}

\subsubsection{Preliminary inventory}

The preliminary inventory included all advertising visible from the road from one direction of traffic on the analysed section. The preliminary inventory was conducted by analysing video footage of the section and using Google Earth. The route has 2881 advertising boards visible from one direction of traffic and located in the roadside.

Table 2. Detailed structure of the route's roadside adverts.

\begin{tabular}{|l|r|r|}
\hline \multicolumn{1}{|c|}{ Type of advertising } & Number & \multicolumn{2}{c|}{ Share } \\
\hline LED & 16 & $0.6 \%$ \\
\hline Trailer & 26 & $0.9 \%$ \\
\hline Flag & 169 & $5.9 \%$ \\
\hline Pylon & 173 & $6.0 \%$ \\
\hline Free-standing & 499 & $17.3 \%$ \\
\hline Banner & 912 & $31.7 \%$ \\
\hline Commercial signs & 1086 & $37.7 \%$ \\
\hline Sum & 2881 & $100.0 \%$ \\
\hline
\end{tabular}

It was established that along the entire route the average spacing between advertising boards is as much as $33 \mathrm{~m}$ with motorways having the biggest spacing of $450 \mathrm{~m}$ and small towns featuring the highest advert density at every $15 \mathrm{~m}$ (Fig. 1). 


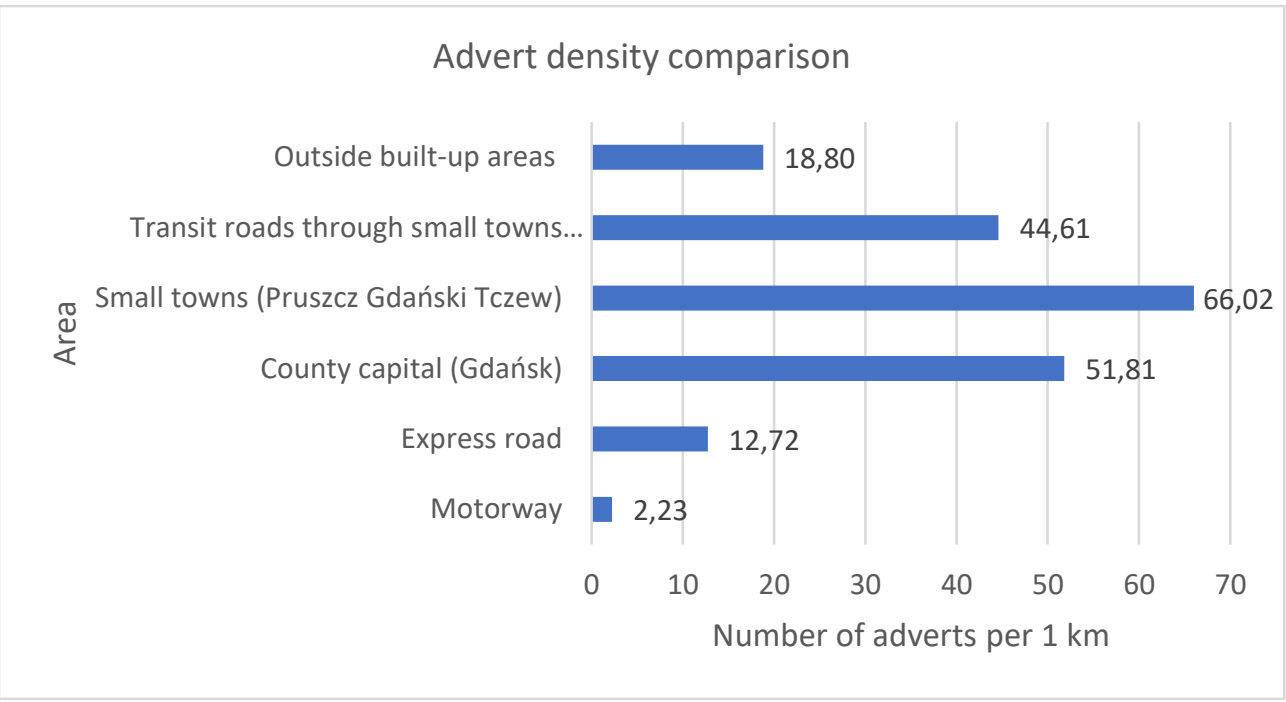

Fig 1. Comparison of advertising density in different functional areas

\subsubsection{Detailed inventory}

A detailed inventory was made of all adverts which were registered to have attracted at least one glance from the study's participating drivers (889). The study was designed to collect these advert parameters:

- width of medium,

- height of medium,

- height of foundation,

- $\quad$ spacing between advert and road,

- angle of advert relative to road axis,

- other.

The average advert along the entire section which was recorded to have attracted drivers' glances was $16.05 \mathrm{~m} 2 \mathrm{big}$. Statistically, the biggest adverts are found on the motorway ( 82.95 $\mathrm{m} 2)$, express road $(30.3 \mathrm{~m} 2)$ and in Gdańsk $(17.65 \mathrm{~m} 2)$. The smallest adverts can be found on transit roads through small towns $(6.43 \mathrm{~m} 2)$. The route's biggest advert was in Gdańsk a net on a façade the size of $334 \mathrm{~m} 2.19 .3 \%$ of the route's adverts were smaller than $2 \mathrm{~m} 2$. The distribution changes significantly from road section to road section. The adverts on the motorway are 30 to $150 \mathrm{~m} 2$ big with express road adverts ranging from 15 to $90 \mathrm{~m} 2$. Those placed on transit roads through small towns are from 2 to $20 \mathrm{~m} 2$. Fig. 2 shows the distribution of advertising sizes.

\subsection{Selecting the study subjects}

It was agreed to test a sample of 60 drivers in three age groups who will also be a crosscutting representation of Polish drivers. In addition, the drivers should feature specific properties related to their age and experience. Table 4 gives the number of people: 60 drivers - broken into 3 groups with 20 people each based on their age. 
Table 3. Groups of drivers in the study sample.

\begin{tabular}{|c|c|c|}
\hline Group I (20 people) & Group II (20 people) & Group III (20 people) \\
\hline Aged: up to 25 & Aged: $30-40$ & Aged: $55-65$ \\
\hline $\begin{array}{c}\text { B category driving license for } \\
\text { not longer than } \\
3 \text { years }\end{array}$ & $\begin{array}{c}\text { B category driving license for } \\
\text { not less than } \\
3 \text { years }\end{array}$ & $\begin{array}{c}\text { B category driving license for } \\
\text { not less than } \\
3 \text { years }\end{array}$ \\
\hline $\begin{array}{c}\text { Active driver - covering at } \\
\text { least } \\
3000 \mathrm{~km} \text { annually }\end{array}$ & $\begin{array}{c}\text { Active driver - covering at } \\
\text { least } \\
3000 \mathrm{~km} \text { annually }\end{array}$ & $\begin{array}{c}\text { Active driver - covering at } \\
\text { least } \\
3000 \mathrm{~km} \text { annually }\end{array}$ \\
\hline
\end{tabular}

Because calibration of 2 people failed, 58 test drives could be made. The entire test included 46 daytime tests $(79 \%)$ and 12 night-time tests $(21 \%)$. The highest number of nighttime tests, i.e. 6 were conducted in age group II with most daytime tests conducted in age group III - at 17.

\subsection{Wearable eye tracker}

To do the tests, a device was bought in a public tender for the project. Made by TOBII, it is called TOBII Pro Glasses 2 [8]. The device consists of a head unit and recording unit (Fig. 3), a control unit and wiring. The control unit was a Toshiba 64GB Encore 2 WT8-B264 8.0 tablet operating on Windows 8.1. The parameters of the eye tracker are as follows:

- Gaze sampling frequency $-100 \mathrm{~Hz}$,

- Field of view - 160 degrees,

- Scene camera - 1080i HD@25fps,

- Scene camera diagonal FOV - 90 degrees 16:9,

- Scene camera: 82 degrees horizontally, 52 degrees vertically,

- 4 eye tracking cameras,

- Binocular eye tracking with continuous parallax compensation,

- 1 point calibration,

- Battery recording time -120 min,

- Measurement accuracy 0.4 degree,

- Latency $<10 \mathrm{~ms}$.
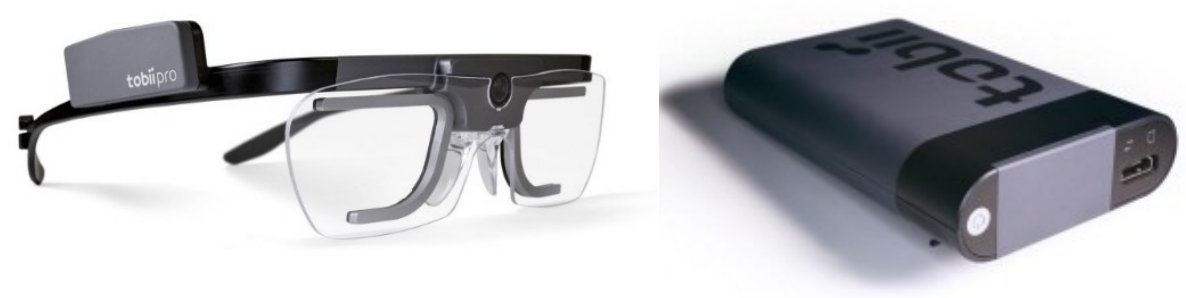

Fig. 3. Tobii Pro Glasses 2. Source: https://www.tobiipro.com. 


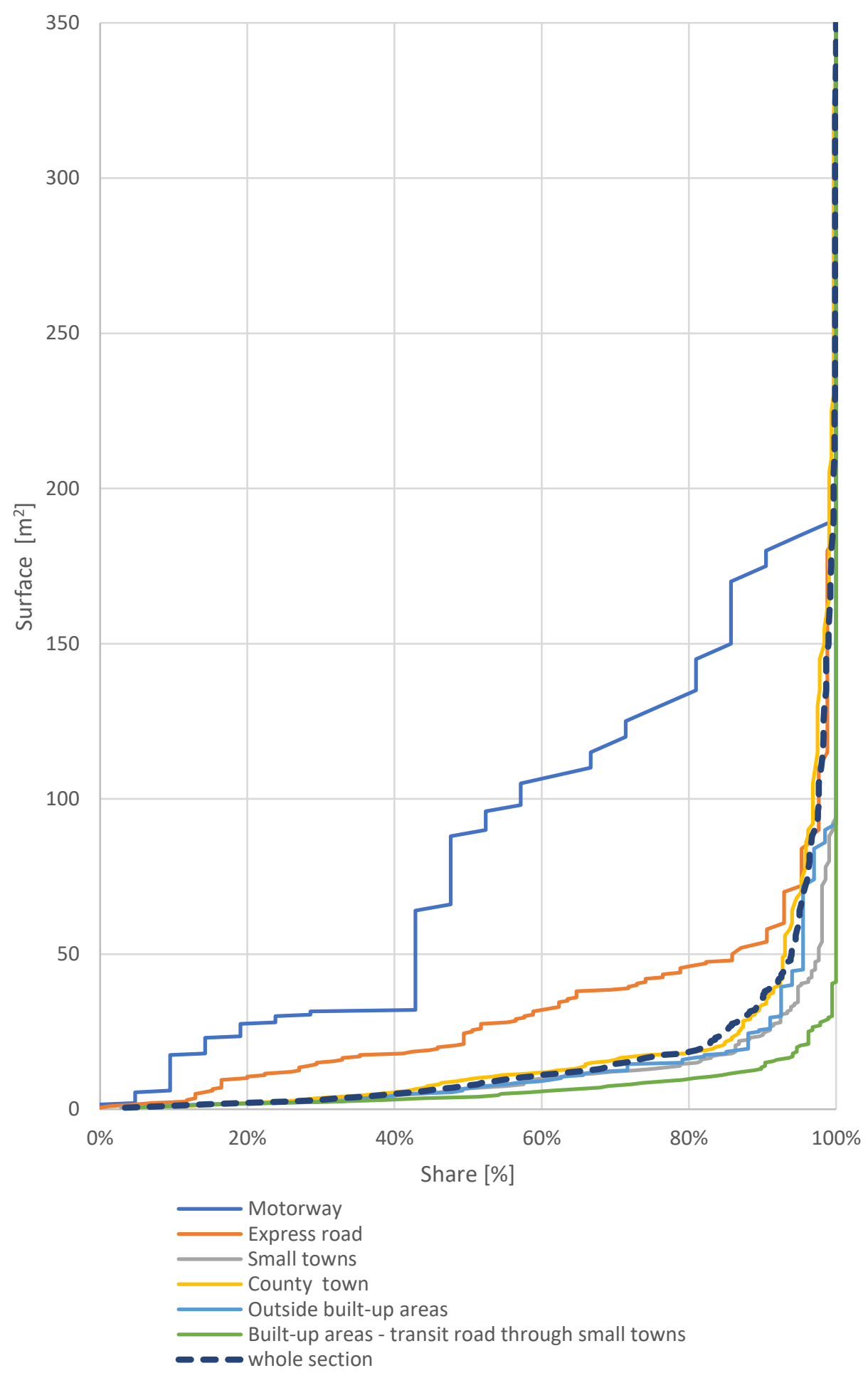

Fig 2. Distribution of advert sizes for different sections 


\section{Results}

Of the 2881 adverts placed along the study section 889 had attracted at least one gaze which is more than $30 \%$. The drivers mostly watched motorway adverts $(60 \%)$ while gazes in the big city of Gdańsk were the rarest (25.1\%) - Fig.4. This may have to do with the complexity of roadside development, traffic and driving tasks. The more a driver is engaged in a driving task, the less time they have to look at advertising. In addition, motorway adverts are large and can be seen from a long distance. They are also placed perpendicularly making watching them easier.

One of the measures in the test is AOI Total Visit Duration [9], further defined as Total Event Time (TET), i.e. the time which a subject spent visiting an AOI (Area Of Interest) from the first to the last eye fixation in a defined AOI, consisting of the duration of eye fixation on an advert, length of eye fixation on the road in the meantime, length of saccades and moments when eyeball movement was not detected.

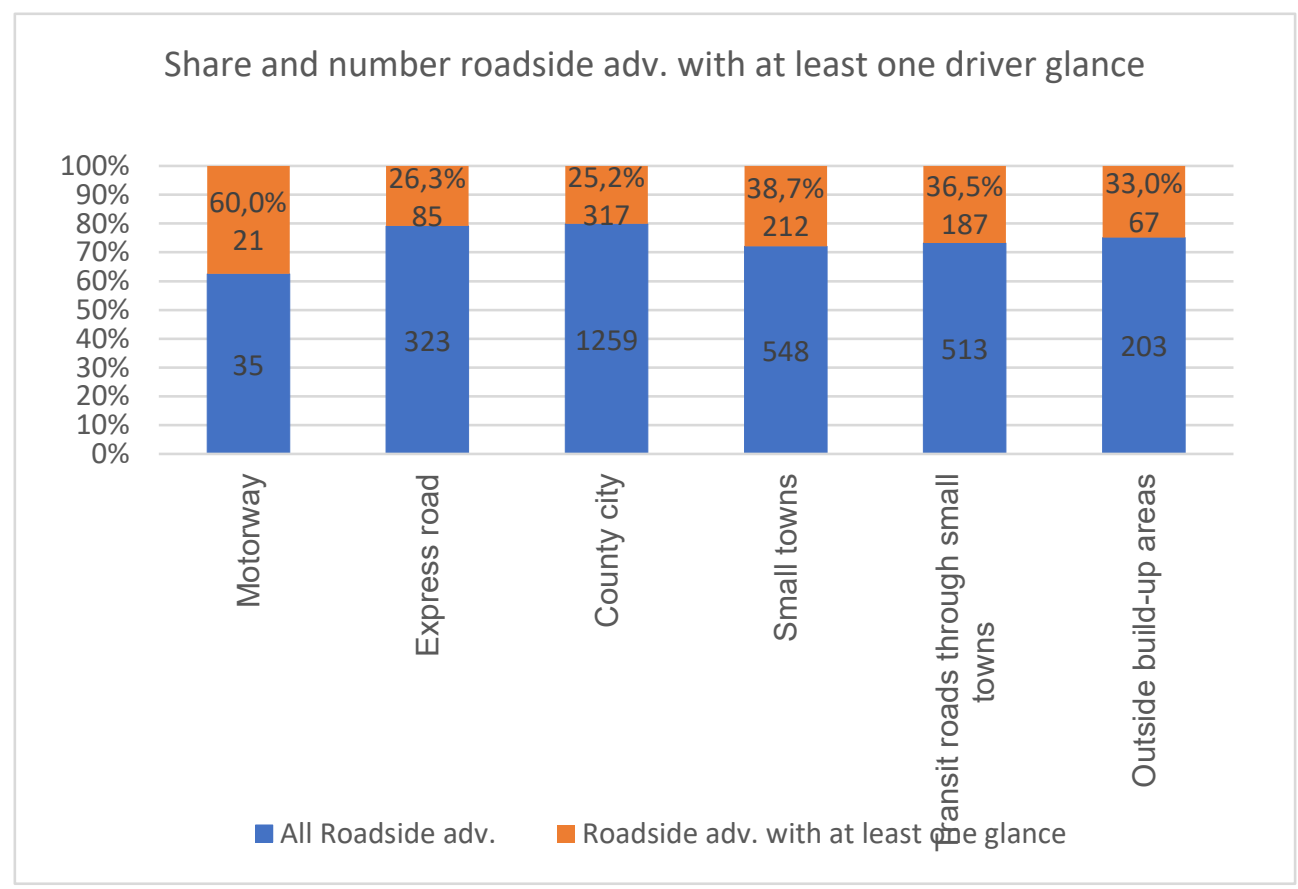

Fig. 4. Share and number of adverts which were recorded to attract driver gazes

The total test time, the duration of the ride for 58 drivers was $94 \mathrm{~h}$. All drivers combined looked at 4282 adverts and 3682 adverts when the vehicles were moving. The total combined TET time for all drivers was $2328 \mathrm{~s}$ (39 $\mathrm{min})$ and $1914 \mathrm{~s}(32 \mathrm{~min})$ when the vehicle was moving. This means that the drivers had spent $0.56-0.69 \%$ of total driving time looking at adverts. Each test started and ended in a car park. This is why the start and end of a recording included in total driving time was not related to research. We can say that the drivers spent on average $1 \%$ of their driving time on reading adverts. This is a very high share of time which drivers spent engaging in other elements of the roadside. The average TET time for all the drivers was $0.52 \mathrm{~s}$ with the maximum at $6.62 \mathrm{~s}$. Figure 5 shows a box plot of the results of gazes of all subjects. The average quartile 1, median and quartile 3 are: $0.19 \mathrm{~s}, 0.33$ and $0.58 \mathrm{~s}$ respectively. The difference in the spread between the drivers is big. In the case of five of the drivers quartile 3 is nearly $1 \mathrm{~s}$. One third of all subjects at least in one case had spent a minimum of $3 \mathrm{~s}$ looking at an advert. 


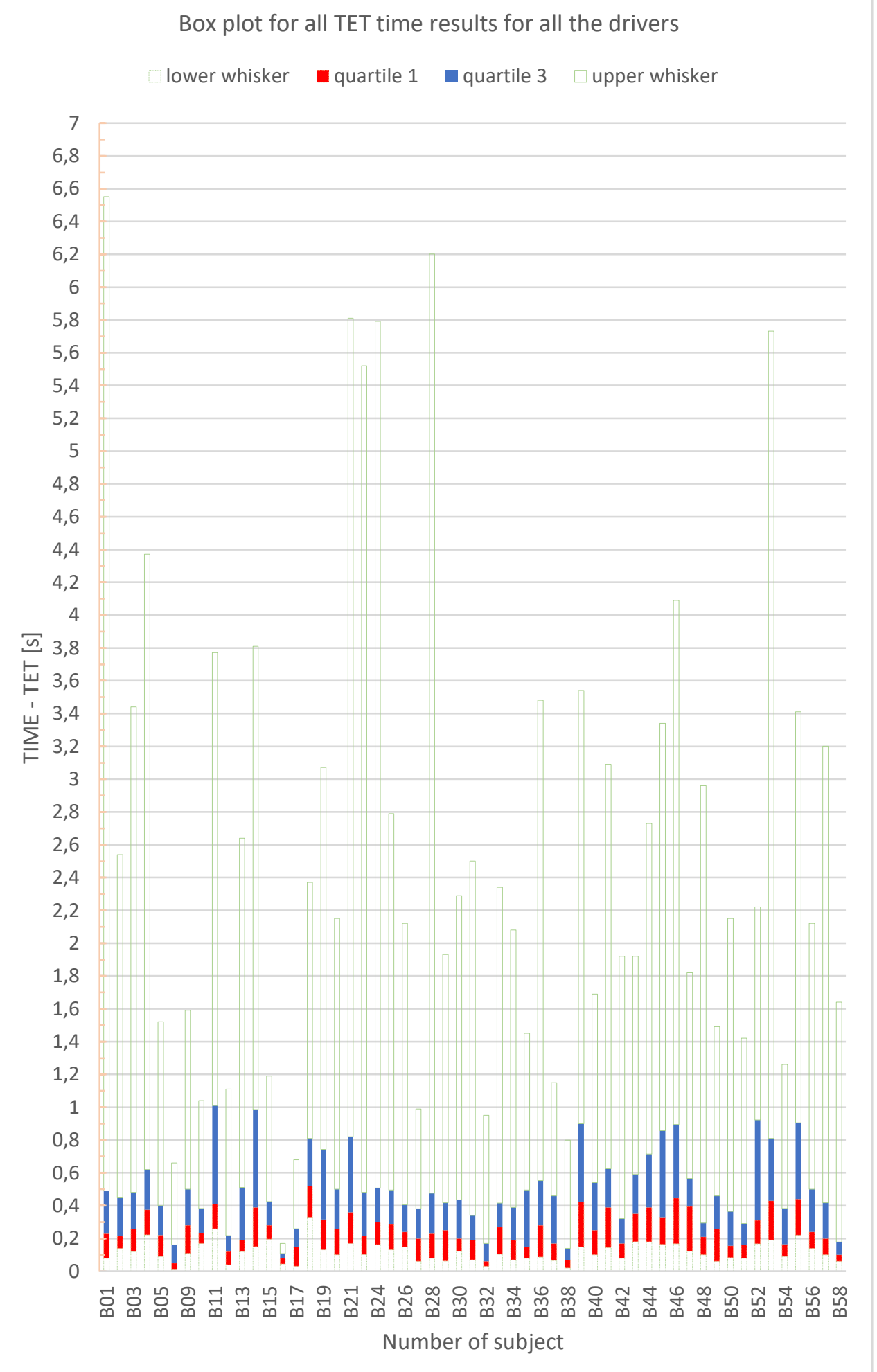

Fig. 5. Box plot for all TET time results for all the drivers 


\section{Conclusion}

The study showed that drivers spend a lot of time looking at adverts which is about $1 \%$ of the entire time spent driving. This may deteriorate driving performance. It was found that the propensity to read adverts does not depend on age. It was demonstrated that while drivers spend less time looking at adverts in night-time, the duration is significantly longer than during the day (average daytime TET is $0.51 \mathrm{~s}$, night-time 0.58). Some drivers are more inclined to look at adverts than others, in two cases the drivers had watched 229 and 257 adverts respectively which represents $7.9 \%$ and $8.9 \%$ of all adverts visible on the route. In addition TET quantiles have the following distribution K50 $=0.35 \mathrm{~s}, \mathrm{~K} 85=0.9 \mathrm{~s}, \mathrm{~K} 90=1.1$ $\mathrm{s}, \mathrm{K} 95=1.7 \mathrm{~s}$. This means that $5 \%$ of advert gazes had a duration of more than $1.7 \mathrm{~s}$ while in $10 \%$ of the cases it was more than $1.1 \mathrm{~s}$. The longest gaze at an advert lasted more than $6 \mathrm{~s}$. If we consider that accidents are very rare and accident causes are very complex with distraction as one of them, the results suggest that advertising is a critical factor causing driver distraction. As a consequence, displaying adverts to drivers should be regulated or banned entirely.

\section{Discussion}

With no additional equipment to monitor vehicle dynamics or the driver's brain activity the study was somewhat limited. More would have been learned if it included stress assessment or driver concentration assessment while watching an advert or shortly afterwards. If combined with vehicle dynamics, the study could establish whether drivers keep the straight line and change driving dynamics as regards speed and spacing to the vehicle before them. The authors believe that another key feature to test is the advert's message. It often seems that the form of advertising display is more important than its position, size, spacing from the road and angle. It is recommended that further work should analyse the content of the message displayed.

\section{References}

1. Safety Impacts of the Emerging Digital Display Technology for Outdoor Advertising Signs. Final Report. NCHRP 20-07/Task 256 (2009)

2. B. Wallace, Driver distraction by advertising: genuine risk or urban myth?, in: Proc. Inst. Civ. Eng., pp. 185-190 (2003). doi:10.1680/muen.2003.156.3.185

3. L. Herrstedt, P. Greibe, P. Andersson, Roadside Advertising Affects Driver Attention and Road Safety, in: Proc. 3rd Int. Conf. Driv. Distraction Ina. Sept. 4-6, 2013, (No. $05-$ P), pp. 1-14 (2013)

4. Act of 21 March 1985 on Public Roads, OJ 2017 Pos. 2222 (Poland, 2017)

5. Dz. U., Act of 7 July 1994 on Construction Law, OJ 2017 pos. 1332 (Poland, 2017)

6. Act of 24 April 2015 amending certain acts on strengthening the tools for landscape protection, OJ 2015 Pos. 774 (Poland, 2015)

7. National Road Safety Programme for 2013-2020 (Polish National Road Safety Council, Warsaw, 2013)

8. Tobii, Tobii Pro Glasses User's Manual, (n.d.)

9. Tobii, Tobii Pro Glasses Analyzer User's Manual, (2015) 